\title{
An Evaluation of the Impact of Wages and Salaries Policies on the Performance of Workers in Kurdistan Public Sector
}

\author{
Hewa Mohammed Majeed \\ Cihan University - Kurdistan Region - Iraq \\ Email: kawa.kamal455@gmail.com
}

\begin{abstract}
The following article examines the strained public sector that has aggravated the fragile economic condition in the Iraqi Kurdistan (KRI) area. The KRI has experienced the resource curse which burdens a lot of the oil-rich regions (Mahdi et al., 2015). An indicator of the curse is that the public sector is overwhelmed and ineffective and this situation may worsen if not addressed. More than half of workers in the region are employed by the public sector, and is increasing both for economic and political reasons. For this reason, the public sector of the Kurdistan Regional Government has become a financial burden on the central budget of the KRG.

Recent articles have discussed strategies to resolve these difficulties, including equitable taxes and subsidy reforms. responding to reduced oil prices; dealing with the economic consequences of decreased oil prices.
\end{abstract}

Keywords: Wages, Salaries, Performance of Workers, Kurdistan, Public Sector. 


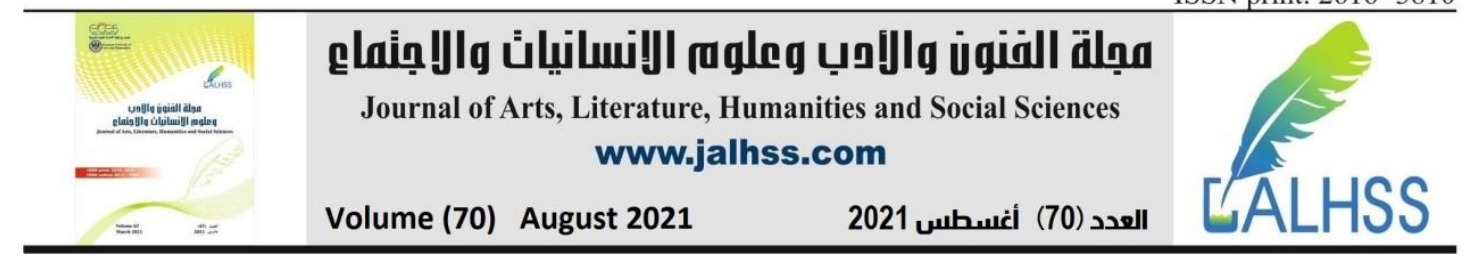

\section{Introduction}

Workers enable organizations and nations to provide or produce goods and services for the ultimate benefit of mankind, while employers provide work for them. This is essentially the process of nation-building. When goods and services are delivered, economic gains are also realized. Employers pay workers for their productivity and services, according to an employment abstract (Irfan, 2009). This has a symbolic value since, just as employees assist employers in making a profit, employers also provide wages and salaries to employees in order for them to accomplish their personal and domestic goals.

The purpose of this study is to assess the impact of wage and salary policies on worker performance in the Kurdistan Public Sector. This project aims to learn about government wage and salary policies in various government sectors. The research will also look into the difficulties faced by government sectors in implementing wages and salaries in Kurdistan. This will be used to determine the impact of wage and salary policies on the performance of government employees. Despite the public sector's contributions, salary advancement remains a challenge (Maduka \& Okafor, 2014). Because of the rising standard of living, there is still a demand for higher pay. The global economic crisis has also sparked a demand for pay raises, which is the driving force behind almost all of the government sector's industrial action.

This study gives information in a simplified form and identifies policy objectives for the management of public wage bills in the region. It gives examples of solutions utilizing secondary data, case studies and outlines the importance of improving management of public wage bills in the region. The objective is to develop a framework for the management of public salary costs by governments. Considering comparison analysis is limited by data limitations, and most results are based on correlations rather than causal effects. The study will create awareness among companies, particularly those in the public sector, about the favorable impact wage and salary policies can have on government workers' performance.

\section{Literature Review}

Wages and salaries are employed as motivators in every workforce. (Dunn \& HoltzEakin, 2000) describe it as a rate system which allows payment of salaries in connection to job done. wages and salaries are no benevolent grant by organization but a vital component of the right of worker in the productivity process. For work done by labor, payment is required. Profit should not be used solely for company growth and development while workers suffer physically and financially (Anene et al., 2017).

According to Maduka \& Okafor, (2014) wage levels should be decided by worker productivity and should cover the regular living expenses of a family of average size. In Kurdistan, wages are currently quite high and, without a doubt, out of step with productivity and labor education levels. There are various reasons that contribute to the quick rise in pricing in general. As a result of the dollarization of the economy, 


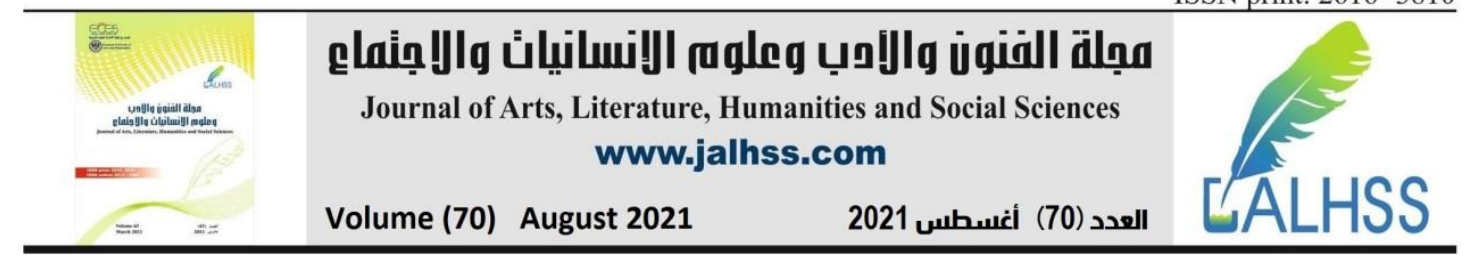

which affected local production and imported commodities costs, the salaries have risen substantially (Hazhar Omer Mohammed, 2019). There is evidence that a low payment environment has an impact on decisions about jobs and factor of production (Wright \& Sylla, 2020). Most of Kurdistan's big companies utilize low-skilled foreign employees in services that local people do not want to accept as they are paid by the government not to accomplish anything. The liberal public employment program has led to the misallocation of vital public resources, poor work ethics, low education pay, massive idleness and the lack of involvement of many Kurds in their economy progress.

Iraq's public salary bill has skyrocketed in recent years, fueled by plentiful employment and generous payment practices. Iraqi governments have undertaken considerable expenditure cuts in reaction to the current drop in oil prices, but these have focused on capital, products, and services, leaving personnel and social expenditures largely unaltered (Razzaq et al., 2019). The government's failure to pay resulted in any reductions in salaries, pensions, or social assistance disbursements. Iraq's public sector compensation (wages and pensions) had expanded faster than that of many comparators by 2016, including regional comparators and oil-exporting emerging countries (Driedger, 2016).

The capacity of the government to regulate public sector size is limited. With no central authority over employment, promotion, unemployment or retirement, there is no central authority. Although there is a legislative structure establishing working conditions, it is not possible to monitor the extent to which expenditure units comply with the law (Kovačević et al., 2020). No central registry of government staff exists and a mismatch exists between the reported salaries and the actual number of staff. The legislature sets the public salary bill as part of the overall budget process. It includes spending on public wages by the federal government, autonomous and semiautonomous agencies, municipalities, and other government entities that are supported entirely or substantially by the budget (Maduka \& Okafor, 2014). The structure of public employee remuneration (the proportions of basic salary, allowances, and incentive bonuses) varies a lot between sectors. Prior to 2011, base salary accounted for less than $20 \%$ of earnings; however, after 2011, the base pay portion has increased, and the allowance system has been simplified. In other industries, such as recreation, culture, and religion, base salaries accounted for more than $80 \%$ of total remuneration in 2015 , but only around $55 \%$ in social security (Mahdi et al., 2015).

Another factor that contributes to higher wages is the informal hiring process, which may not be open and determined through a competitive process or by following salary scale guidelines, but rather on an individual basis and influenced by how employees are hired through recommendations from higher ranks (Maduka \& Okafor, 2014). If this is correct, a job market will emerge as a result of people in decisionmaking positions swapping services, and it will be a question of recruiting relatives and friends who do not reveal unethical work practices at government agencies 


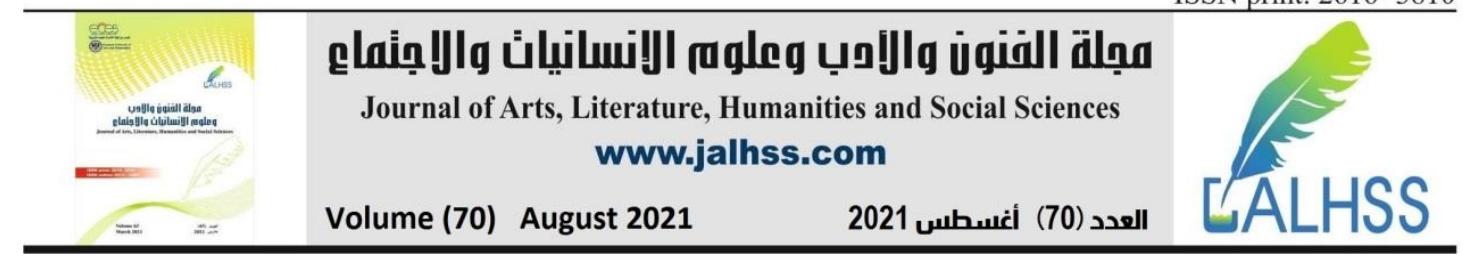

(Kovačević et al., 2020). This will result in the emergence of a corrupt system that threatens the accountability of public organizations. Because there are jobs that are available almost solely in the public sector, wages may be a preferential choice for family and friends rather than for the skills and education of staff. Education is not a qualifying criterion in a system, but rather a degree to legitimize employment in a profession that the employer has no special capabilities.

Regional economic and governance difficulties are causing major unpredictability in terms of the size and expense of the payroll (Mahdi et al., 2015). The size of the defense and security sector is unknown, partly due to the shifting relationship between the government and non-governmental militias, and partly due to the fact that reporting standards in this sector are even less developed than in civilian areas, with the possibility of large numbers of fictitious employees and rank inflation (Gutsalenko et al., 2020). It is also difficult to determine the amount and structure of public sector employment in the country as a whole due to a lack of information flow between the central government and the Kurdistan Regional Government.

In addition to the rise of the payroll, the wage bill has grown due to an increase in average compensation per employee in real terms. Despite the fact that the education and health sectors absorb the largest proportion of the wage bill, education and health service delivery outcomes are inconsistent. The salary premium for working in the public sector is low, and wages vary greatly between industries. Government employees in public administration earn the highest average income, while those in the education sector earn the lowest (Akpan, 2021). Medical staff in the public sector seems to have the greatest earnings in comparison to the private sector, whilst teachers and other government employees appear to have the lowest wages.

The productivity of work is extremely poor as a result of a corrupt employment system, lack of jobs, weak work ethics and inadequately qualified individuals. Low labor productivity, together with high employment and wages, has a strong effect on weak economic growth and living standards and represents one of the main drivers of excessive inflation (Ali Almohtaseb et al., 2020). Low labor productivity and a high wage rate constitute two major challenges, not only disinclining external direct investment, but leaving the region to finance developments elsewhere. They also prevent domestic investors from investing because they may have greater investment prospects abroad (Kovačević et al., 2020). In Kurdistan, labor cost does not exist as a competitive component in production. The region's high labor costs and inflation rate deter investment.

\section{Methodology}

This study will entail a desk or secondary research based on current data. Secondary data refers to data acquired for other than this specific study previously. The researcher chose to employ desk research to avoid acute health risks to himself or any subject, because of limits induced by constraints on movement. The approach is also simple to implement, extremely cost-effective and can be completed within the 


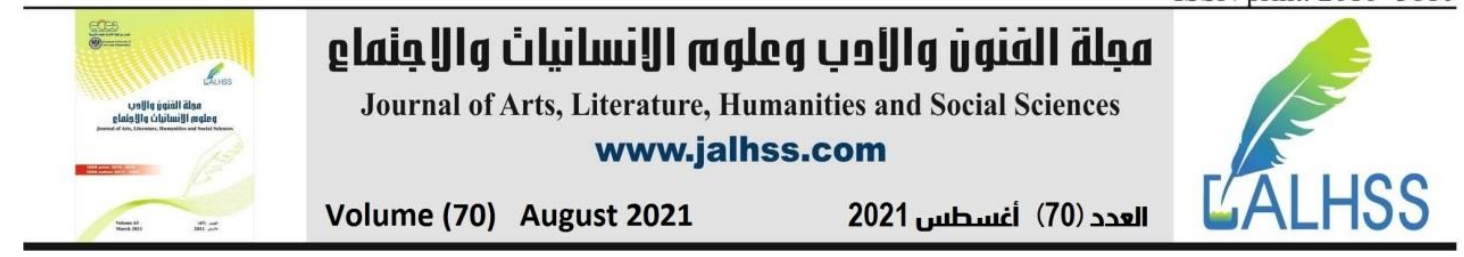

timeframe for this study. Secondary data is research information that has been published in journals, reports, or other related publications and has provided a simple and effective way for the researcher to complete the study. (Argus, 2020) The data gathered from secondary sources will be summarized and compiled to improve the research's overall feasibility and efficacy. This research will be based on a large amount of electronic academic content obtained from online academic databases. In addition, the study will employ internet accounts, databases, and rating systems to come to a conclusion.

The first stage, like with any other study project, is to identify and define the research topic. This approach is looking through existing literature to see what has been stated about the issue and any gaps in the field of research. This procedure aids the researcher in determining the best and most dependable source for the information sought, as well as the best method to frame the research problem (Jennings \& Allen, 2016). The researcher must establish the research area and construct or select the research questions that the study must address at the conclusion of the investigation. The collecting of existing data is the second step in the procedure. This entails determining the most appropriate data sources and determining which data sources can be successfully linked to the study's goal.

The researcher must have a thorough understanding of the data as well as the reasons why the particular set of data is relevant to the study at hand. This procedure entails identifying, selecting, analyzing, linking, and linking data sets in order to achieve the study's goals. The researcher should proceed to the existing data gathering process and then break it down for concrete research outcomes after successfully identifying the source and area of inquiry. The researcher then compares and standardize existing data from various sources. To effectively comprehend how to use the provided set of data, the researcher must read anything relevant to data that they can get their hands on. Data analysis is the last phase in the procedure. Theoretical analysis was used in the data analysis. The researcher will analyze the study findings and assess whether the data is sufficiently relevant to the research topic at this level. The researcher has complete freedom to review current data in order to get actionable insight into the research issue. Secondary research has a number of limitations. While secondary data makes use of freely available information, it is clear that credibility assessment is required to evaluate information validity. Furthermore, not all secondary data sources may provide the most up-to-date information and reports. Furthermore, the reliability of secondary research is heavily reliant on the reliability of primary research.

\section{Findings}

\begin{tabular}{|l|l|}
\hline Author & Kovačević M, Blagojević S, Kuzmanović B \\
\hline Title & $\begin{array}{l}\text { Sustainability of the motivation policy model for employees in state } \\
\text { administration }\end{array}$ \\
\hline Source & European Journal of Business and Management \\
\hline
\end{tabular}




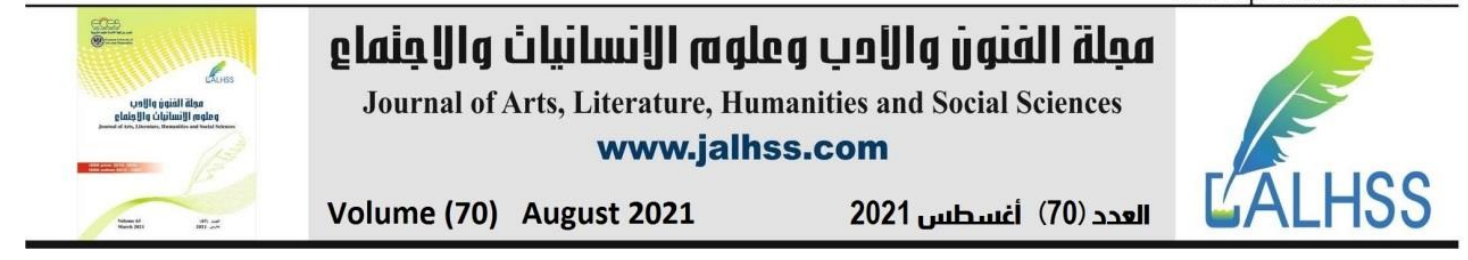

\begin{tabular}{|c|c|}
\hline Methodology & $\begin{array}{l}\text { The research made use of secondary data, questionnaires and content } \\
\text { analysis. }\end{array}$ \\
\hline Findings & $\begin{array}{l}\text { The retention and improvement of the employee motivation policy } \\
\text { model is a critical requirement for the long-term performance of } \\
\text { organizations in the public and private sectors. Workplace motivation } \\
\text { has a tremendous impact on the success of modern businesses; the } \\
\text { impact is multifaceted and complex, and it has been scientifically } \\
\text { proved. Motivation is influenced by a variety of factors with varying } \\
\text { degrees of influence and hierarchy, which are dependent on } \\
\text { socioeconomic situations and cultural variables, as well as personnel } \\
\text { qualities, which must be regularly monitored. The study gives a long- } \\
\text { term model of employee motivation in government, as well as the } \\
\text { findings of research into the hierarchy and the impact of motivation } \\
\text { variables on employees with various demographic features. }\end{array}$ \\
\hline Author & Ifran M \\
\hline Title & Pakistan's wage structure, during 1990-91-2006-07 \\
\hline Source & Journal of Balkan and Near Eastern Studies \\
\hline Methodology & Qualitative review of past publications and Primary data analysis \\
\hline Findings & $\begin{array}{l}\text { According to data from labor force surveys, this article seeks to record } \\
\text { changes in salary levels for several types of employees employed in } \\
\text { various segments of the labor market from 1990-91 to 2006-07. Wage } \\
\text { structure can be examined from a variety of perspectives. They examine } \\
\text { the levels and patterns in a variety of industries. Worker characteristics } \\
\text { such as sex, education, age and occupational categories are further } \\
\text { subdivided along the formal/informal boundary. The impact of } \\
\text { unionism, as well as other regimes' labor and pay laws, on wage } \\
\text { outcomes is also examined. At the aggregate level of the economy, } \\
\text { there appears to be a correlation between money wage growth and GDP } \\
\text { growth. }\end{array}$ \\
\hline Author & Gutsalenko L, Mokiienko D \\
\hline Title & Modern remuneration system in foreign country \\
\hline Journal & Bioeconomics and Agrarian Business \\
\hline Methodology & Quantitative Descriptive Statistics \\
\hline Findings & $\begin{array}{l}\text { The report examines how modern pay systems are formed, taking into } \\
\text { account the key components and techniques of labor organization in } \\
\text { other nations. In some foreign nations, it also defines the requirements } \\
\text { for mandatory pay increases. The article focuses on observers' } \\
\text { predictions for remuneration level changes and the emergence of five } \\
\text { trends in employee salary and additional payments, including: regular } \\
\text { performance bonuses; transparent remuneration; more employees will } \\
\text { receive bonuses; equity analysis aimed at remuneration payments; and } \\
\text { the formation by states of their own minimum wage policy. It argues } \\
\text { that growing political influence on the formation of minimum salaries }\end{array}$ \\
\hline
\end{tabular}




\begin{tabular}{|c|c|}
\hline 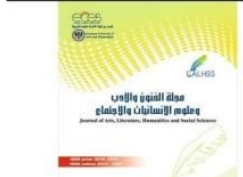 & 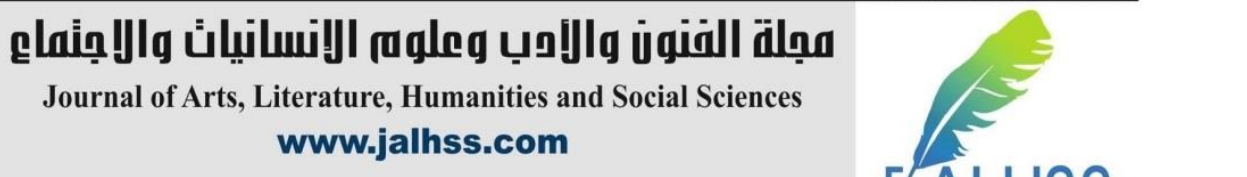 \\
\hline$=$ & Volume (70) August 2021 \\
\hline & $\begin{array}{l}\text { has resulted in a beneficial economic development and an increase in } \\
\text { demand among states. }\end{array}$ \\
\hline Author & Maduka C, Okafor D \\
\hline Title & Effect of Motivation on Employee Productivity \\
\hline Journal & International Journal of Managerial Studies and Research \\
\hline Methodology & $\begin{array}{l}\text { Secondary data, questionnaires, and content analysis were used in the } \\
\text { study. }\end{array}$ \\
\hline Findings & $\begin{array}{l}\text { This research attempts to examine the role of motivation in the } \\
\text { management of people at work; no system can function properly } \\
\text { without it, and no company can achieve its goals without motivating its } \\
\text { employees. As a result, the goal of the research is to determine the } \\
\text { impact and methods for inspiring employees in the workplace. }\end{array}$ \\
\hline
\end{tabular}

\section{Discussion}

The government must implement policies that address both the amount of the salary and in a lesser way the degree of offset in order to regulate the determinants of the possible future increase in the public sector wage bill. Since salary development has been the key driver of the growth in the wage bill in the past 10 years, reform should focus on this element of the administration of the salary bill (Razzaq et al., 2019). Although the low-inflation state makes it harder to cut actual pay, it can help reduce future wages by reorganizing and re-calibrating public sector pay and supplements. The public sector compensation premium is relatively low, about $10 \%$. Benefits might be scaled away without endangering a widespread exodus from state employment because of lack of alternative private sector and of availability of nonwage pensions (such as medical insurance and generous old-age pensions) (Gutsalenko et al., 2020). In this area, the main focus should be on the improvement of the connection between performance and remuneration.

To alleviate the inflated public sector workforce, sector-specific initiatives and a business environment that encourages private sector hiring will be required. Addressing the bloated public wage bill while also increasing the quality of stateprovided public goods would necessitate sector-specific remedies. For example, health care is severely understaffed, whereas higher education employment levels can only be justified if enrollment rates improve (Irfan, 2009). The government must fight the economically unwise impulse to increase the public sector and employment by state-owned firms since demobilization is projected to put supply pressure on the labor market (Indartono \& Faraz, 2019). A functional and procedural assessment, as well as a medium-term human resource plan, will be required for such a diversified approach. It will also imply enhancing the business environment in order to create jobs for Iraq's rising labor force as well as those working in the public sector whose jobs are no longer required or affordable. 


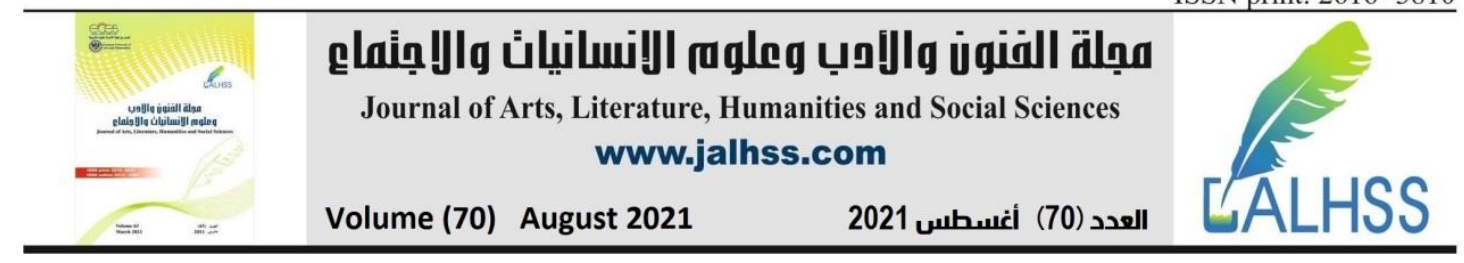

The government should undertake a staff reduction plan through early retirements as a short-term employment strategy. This strategy would not result in a complete hiring halt, but it would prohibit automatic filling of posts that became empty due to retirement or other factors (Kovačević et al., 2020). The success of this policy is determined by the age distribution of government employees and the hiring flexibility preserved at higher levels of decision-making (Mahdi et al., 2015). As a one-time solution, the government may need to contemplate outright personnel reductions combined with voluntary early retirement. This approach would be most effective in areas where service outcomes are unrelated to population growth, economic activity, or security, or when services have been curtailed or outsourced out to the private sector. Voluntary retirement programs, on the other hand, can only achieve their goals if there is a genuine danger of layoff.

Payments and financial decisions should be subjected to budget authorization as a matter of commitment control. This could take the form of a joint authorization between the employing department and the Ministry of Finance for the purpose of simplicity (Gutsalenko et al., 2020). A central human resource management organization or a civil service and public employee commission would be in charge of enforcing uniform hiring, promotion, and termination regulations. There is a need for regulations that impose legal and financial consequences for unapproved and unlawful employment decisions, possibly retroactively with a brief grace period.

Total remuneration should rely less on allowances to better reflect performance and make the wage scale more transparent. Allowances are a typical way to conceal the actual payment of public sector employees, to provide supervisors more freedom in differentiating emoluments without necessarily reflecting performance, and to reduce the relation between remuneration and responsibilities and employee performance. Allowances should be amalgamated with salaries as part of the human resource strategy, with nonwage payment limited to performance-based, periodic bonuses (Mahdi et al., 2015). A regional effort and an economic environment to promote the hiring of private sector helps to alleviate the inflation of the public sector. Specific sectoral solutions are required to address the blowing public wages law while simultaneously improving the quality of the products delivered by the State. Higher education jobs can only be justified if the rate of enrolment improves, for example, is grossly under personalized (Mahdi et al., 2015). As a result of the expected mobilization, the government needs to fight against the economically imprudent stimulus to boost the government sector and employment of state-owned enterprises.

Given its large debt, the country has to free up budgetary space in order to avoid crowding out spending, promote inclusive growth, and build up buffers for unforeseen future shocks. To maintain the country's debt manageable, fiscal consolidation is required (Indartono \& Faraz, 2019). One of the most critical aspects of the consolidation program is keeping the public pay bill under control, because the public pay expenditure is rising without providing the required public service outcomes, particularly in education. Increased access to postsecondary education and 


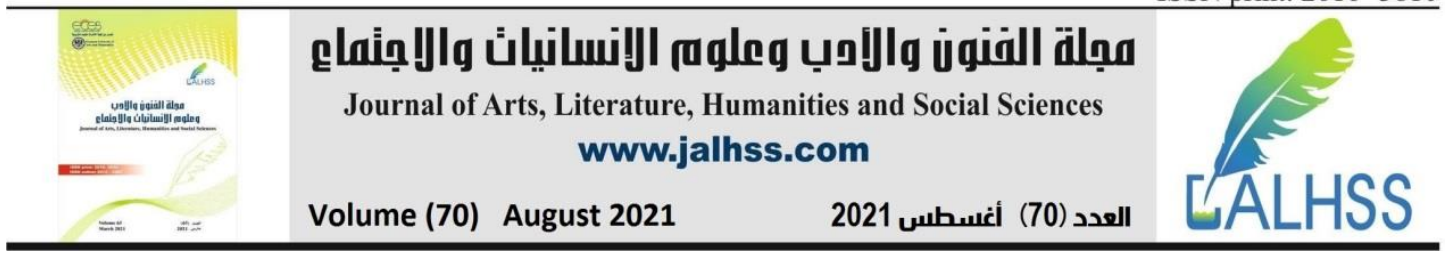

vocational training would be critical in this area for minimizing skill mismatches and improving the country's medium-term growth prospects. Progress has been slow till now in changing the public wage bill and there have yet been no tangible outcomes. Since an election year in 2017, there have been no improvements in this sensitive issue. Experience from other nations suggests that high-level political will is important if a hard reform agenda is successfully implemented in the management of public salary bills. In addition, in order to succeed, the change should be thorough, sequenced and integrated with a thoroughly considered communication plan.

\section{Conclusion and recommendation}

Across the Middle East and Central Asia, economic and social issues have become more severe. Despite a healthier global economy, the region's growth prospects remain bleak. Weak economic growth and high unemployment put pressure on the government to absorb labor market slack, while deteriorating budget conditions need adjustments. At the same time, governments must work toward the SDGs, and public pressure to enhance public service delivery and access is growing, owing in part to young demography and large intakes of refugees and migrants. These pressures will only increase in the future. Policymakers in the region are attempting to find methods to fund programs that address these issues. Since the monetary sector is declining as a result of large inflows of refugees, increased security risks, lower oil prices, national authorities are increasing efforts to raise fairer revenue and adjust expenditure in support of pro-infrastructure spending, while ensuring appropriate social protection. Recent articles have discussed strategies to resolve these difficulties, including equitable taxes and subsidy reforms. responding to reduced oil prices; dealing with the economic consequences of decreased oil prices.

\section{References}

1. Akpan, N. (2021). The Role of Incentives on the Performance of Health Workers in a Public Sector Organization in Abuja, Nigeria. Jurnal Ilmiah Ilmu Administrasi Publik, 11(1). https://doi.org/10.26858/jiap.v11i1.19111

2. Ali Almohtaseb, A., A Kareem Shaheen, H., Mohummed Alomari, K., \& Yousef Almahameed, M. A. (2020). Impact of Talent Management on Organizational Performance: The Moderating Role of an Effective Performance Management System. International Journal of Business and Management, 15(4). https://doi.org/10.5539/ijbm.v15n4p11

3. Anene, P., Obasi, J., \& Nicholas, I. (2017). Impact of Effective Wages and Salary Administration on Civil Service Productivity in Nigeria: A Study of Anambra State. Asian Journal of Applied Science and Technology (AJAST), 1(9).

4. Argus. (2020). Methodology overview Methodology rationale. Argus European Natural Gas. 


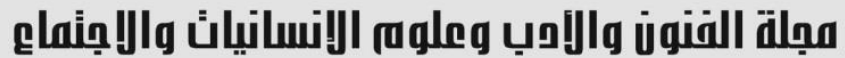 \\ Journal of Arts, Literature, Humanities and Social Sciences www.jalhss.com

5. Driedger, L. (2016). 1. The Global Challenge. In Mennonites in the Global Village (pp. 1-22). University of Toronto Press. https://doi.org/10.3138/9781442677234-003

6. Dunn, T., \& Holtz-Eakin, D. (2000). Financial capital, human capital, and the transition to self-employment: Evidence from intergenerational links. Journal of Labor Economics, 18(2). https://doi.org/10.1086/209959

7. Indartono, S., \& Faraz, N. J. (2019). The role of commitment on the effect of public workers' OCBO on in-role performance. Administratie Si Management Public, 2019(32). https://doi.org/10.24818/amp/2019.32-08

8. Gutsalenko, L. V., \& Mokiienko, D. O. (2020). Modern remuneration system in foreign country. Bioeconomics and Agrarian Business, 11(1), 40-47.

9. Irfan, M. (2009). Pakistan's wage structure, during 1990-91-2006-07. PIDE Working Papers, 54, 1-59.

10. Jennings, J. R., \& Allen, B. (2016). Methodology. In Handbook of Psychophysiology, Fourth

Edition. https://doi.org/10.1017/9781107415782.027

11. Kovačević, M., Blagojević, S., \& Kuzmanović, B. (2020). Sustainability of the motivation policy model for employees in state administration. Sustainability (Switzerland), $12(19), \quad 1-29$. https://doi.org/10.3390/su12197974

12. Maduka, C. E., \& Okafor, Dr. O. (2014). Effect of Motivation on Employee Productivity. International Journal of Managerial Studies and Research (IJMSR), 2(7), 137-147.

13. Mahdi, S. M., Sourchi, R., \& Liao, J. (2015). Understanding High Performance Work System (HPWS) as Related to creativity and Job Engagement in Kurdistan and Canada. European Journal of Business and ManagementOnline), 7(20).

14. Razzaq, S., Shujahat, M., Hussain, S., Nawaz, F., Wang, M., Ali, M., \& Tehseen, S. (2019). Knowledge management, organizational commitment and knowledge-worker performance: The neglected role of knowledge management in the public sector. Business Process Management Journal, 25(5). https://doi.org/10.1108/BPMJ-03-2018-0079

15. Wright, R. E., \& Sylla, R. (2020). Wages and Salaries. In The History of Corporate Finance. https://doi.org/10.4324/9781003074212-6 